
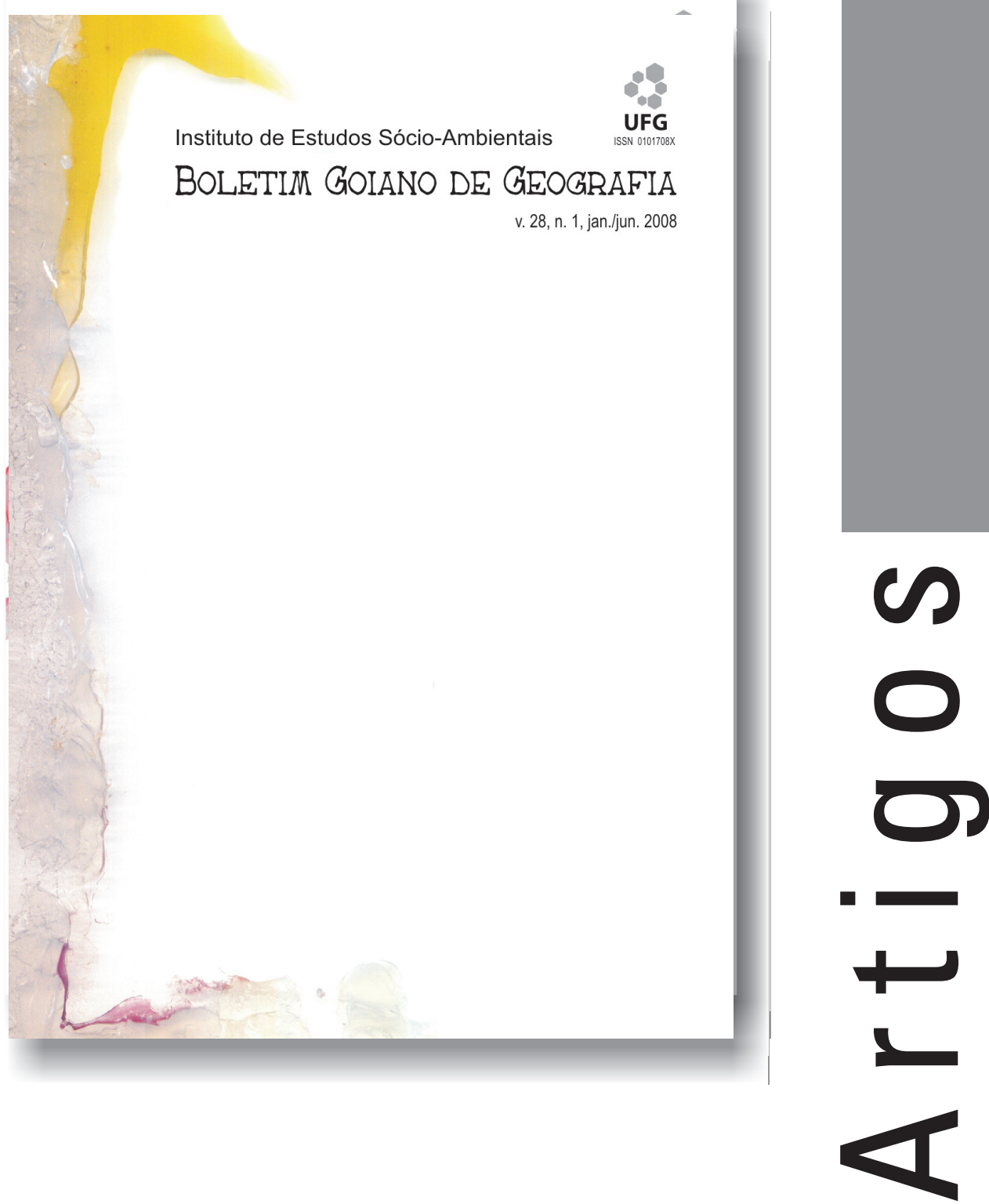


\title{
Estudo dos impactos ambientais como subsídio para o planejamento das trilhas do parque nacional na serra de Itabaiana, SE
}

\author{
Study of evironmental impacts as subside for tracks plannnig at Serra de Itabaiana National \\ Park, SE
}

Ivana Silva Sobral Oliveira - Universidade Federal de Sergipe

ivanasobral@hotmail.com

\section{RESUMO}

As Unidades de Conservação (UC's) são essenciais para a preservação dos recursos naturais, uma vez que nelas encontram-se ecossistemas ameaçados e biodiversos que têm garantias legais de proteção. Para assegurar tal proteção, é necessário que haja planejamento e gestão eficientes. Em áreas protegidas em que a visitação é permitida deve-se utilizar metodologias de avaliação dos impactos para que o uso público aconteça sem comprometer a resiliência dos ecossistemas. Nesse sentido este trabalho objetivou mapear as trilhas de uso público, caracterizar os impactos e determinar os critérios de uso das duas trilhas do Parque Nacional Serra de Itabaiana (PARNASI) mais visitadas. Para isso utilizou-se a metodologia LAC - Limite Aceitável de Câmbio. Através do $L A C$, verificou-se que as trilhas mais visitadas do parque já apresentam sinais de que a capacidade de suporte esta próxima ou ultrapassando seu limite, podendo prejudicar a qualidade da visitação, a segurança dos visitantes $\mathrm{e}$ gerar degradação ambiental. Dessa maneira, as matrizes de monitoramento das trilhas propostas são ferramentas importantes para a proteção dos recursos naturais, uma vez que podem auxiliar os administradores do parque na seleção de estratégias de manejo que garantam a sustentabilidade dos ecossistemas do parque.

Palavras-chave: planejamento ambiental; uso público; limite aceitável de câmbio; matriz de monitoramento, áreas protegidas

\begin{abstract}
Protected areas are essential for natural resources preservation, once several threated ecosystems and biodiversity are shelted for that legal guarantee of protection. For assure this protection it is necessary an efficient planning e administration. Protected areas in witch visits are allowed, impact evaluation methodology must be used so that the public use happens with no implications for $r$ environment at all. Looking for this meaning point, this work aimed to characterize those impacts and determinate criterions of use for National Park tracks, as well, elaborate cognitive maps and of tables of impact monitoring. For this, was used the methodology LAC - acceptable changing limit. Using LAC, it was seen that most visited tracks in park already shows indications that its support capacities are near or trespassing own limits, what might affect the quality of visiting, visitor safety and result in environmental damage. So, the monitoring matrix of proposed tracks are important tools natural resource protection as it is able to help Park administration in the selection of management strategy witch make the park sustainability sure.
\end{abstract}

Key-words: environmental planning; public use; acceptable changing limit; monitoring matrix, protected areas

\begin{tabular}{|l|c|c|c|c|c|c|}
\hline Boletim Goiano de Geografia & Goiânia - Goiás - Brasil & v. 28 & n. 1 & p. 115-126 & jan. / jun. & 2008 \\
\hline
\end{tabular}




\section{Introdução}

O número de visitantes em ambientes naturais tem aumentado significativamente nas últimas décadas em decorrência da busca do relaxamento e lazer que não são encontrados nos centros urbanos. Com a crescente procura pelas Unidades de Conservação (UC’s), são necessárias que diretrizes para o planejamento e gestão do uso público sejam traçadas. Só assim, um dos principais objetivos das UC's - a conservação in situ da biodiversidade - poderá ser cumprido, e programas de educação ambiental efetivados de maneira eficiente.

Considerando que a visitação altera o ambiente natural, é necessário que se tenha um planejamento que atenda o princípio da viabilidade ambiental, segundo o qual o uso público deve ser praticado com o controle dos impactos para não acarretar alterações irreversíveis na área visitada. Segundo Takahashi (2006), um bom método para o controle dos impactos de visitação é aquele que proponha pelo menos a definição de indicadores de impactos ecológicos e recreativos, o estabelecimento de limites aceitáveis de impactos e a elaboração de um programa de monitoramento. No entanto, para que haja efetivação do planejamento deve existir o bom senso do administrador da UC para monitorar os impactos de acordo com a freqüência de monitoramento sugerida no planejamento.

O princípio da viabilidade ambiental não faz parte da realidade do Parque Nacional Serra de Itabaiana (PARNASI), uma vez que lá não tem ocorrido o devido planejamento e monitoramento dos impactos, que são essenciais para a elaboração de estratégias de proteção dos seus recursos naturais. A ausência destes instrumentos de gestão pode acarretar danos irreparáveis nos ecossistemas do parque. Convém ressaltar que o único "controle" que existe é um livro de registro na entrada principal do parque, no qual, no ano de 2006, foram levantados 19.993 visitantes. Sabe-se que esse número é subestimado porque não considera as várias outras entradas da Serra de Itabaiana que se constituem em diversas trilhas.

Diante de tal realidade, o presente trabalho objetivou caracterizar os impactos e determinar os critérios de uso das trilhas de uso público mais freqüentadas do Parque Nacional Serra de Itabaiana, bem como, elaborar planilhas de monitoramento dos impactos. 


\section{Material e métodos}

\section{Área de estudo}

O Parque Nacional Serra de Itabaiana, situado a $10^{\circ} 25^{\prime} 15^{\prime \prime} S$ e $37^{\circ} 25^{\prime} 15$ ”O, ocupa uma área de 7966 ha nos municípios de Areia Branca, Itabaiana, Laranjeiras, Itaporanga d' Ajuda e Campo do Brito. É composto pelas serras do Cajueiro, Comprida e de Itabaiana (Figura 1), sendo esta última a área em que as trilhas do Poço das Moças e Gruta da Serra estão localizadas.

A vegetação do parque é variada, constituída basicamente por quatro tipos fisionômicos: restingas em áreas arenosas, cerrado com espécies arbustivas, campos rupestres e Mata Atlântica com formas arbóreas. Há também áreas muito úmidas e periodicamente alagadas, assim como locais em que a ação antrópica modificou a fisionomia vegetal nativa, que são os palmeirais e os agroecossistemas (Vicente et. al, 1997).

Segundo Carvalho e Vilar (2005), as informações sobre a fauna do parque se resumem nos estudos sobre hábitats e alimentação de lagartos (Ramos; Denisson, 1997; Fernandes; Oliveira, 1997), diversidade de artrópodes de solo (Amâncio; Ramos, 1997), microhábitats de aranhas e descrição de Nothroctenus fuxico (Dias; Brescovit, 2004). 
28, n. 1: 115-126, 2008

Artigo

$\left.119\right|_{\infty} ^{\circ}$

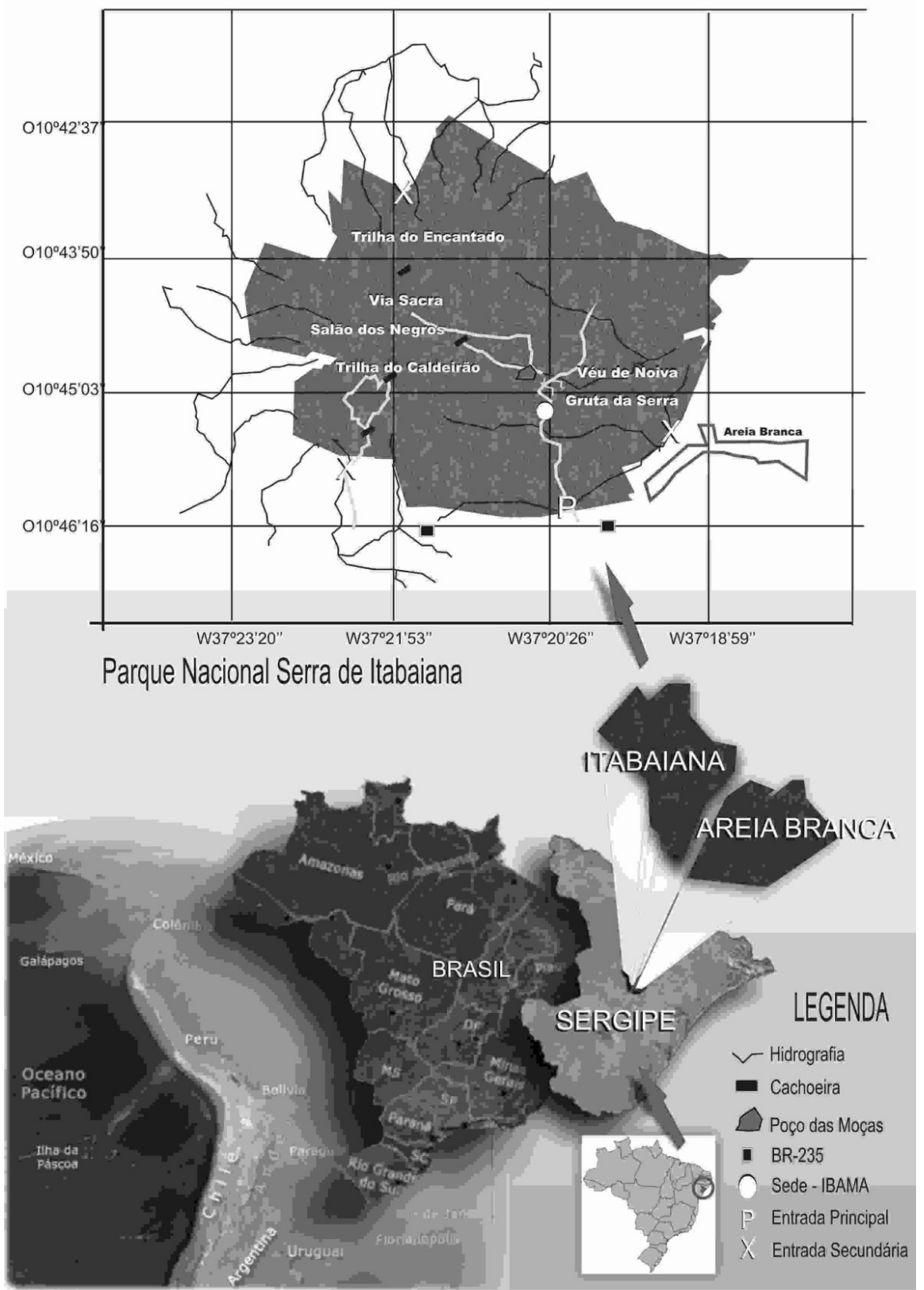

Figura 1: Mapa da Serra de Itabaiana, Parque Nacional Serra de Itabaiana, SE. (Fonte: Sobral et.al, 2007). 


\section{Coleta e análise das informações}

\section{Limite Aceitável de Câmbio (LAC)}

As trilhas previamente mapeadas foram caracterizadas pela metodologia conhecida como Sistema de Planejamento Limite Aceitável de Câmbio - LAC, desenvolvido por Stankey et al. (1985), no qual foram identificados indicadores de impacto que serviram para determinar o limite aceitável das mudanças provocadas pelo uso público. Estes dados serviram como base para a elaboração de matrizes de planejamento (Takahashi; Cegana, 2006) que estabelecem estratégias de manejo para minimizar os impactos encontrados nas trilhas do parque.

A matrizes de planejamento foram elaboradas com base nos diversos impactos das diferentes trilhas. Servem para que o órgão gestor do parque monitore as trilhas de acordo com as freqüências de monitoramento sugeridas nas matrizes e aplique as ações de manejo sugeridas assim que o limite aceitável de câmbio for atingido (Quadro 1).

As etapas de caracterização dos impactos negativos das trilhas foram realizadas da seguinte maneira:

- Inventário das trilhas e as condições existentes: as trilhas e as condições encontradas foram detalhadas e organizadas em planilhas segundo a orientação de pontos com características significativas, tais como impactos relevantes, bifurcação, declividade, largura do leito, erosão, trecho perigoso, obstrução do leito da trilha.

- $\quad$ Seleção dos indicadores de impactos das trilhas: os indicadores foram selecionados a partir do inventário das trilhas. Dessa maneira, selecionaram-se indicadores que ao mesmo tempo em que fossem significativos para cada trilha específica, pudessem ser quantificados de maneira prática e barata. Os indicadores são dinâmicos, de maneira que quando o órgão gestor for realizar o monitoramento dos impactos, se for verificado que o impacto relacionado ao indicador for cessado, o indicador deve substituído por um que esteja atrelado ao impacto da trilha.

- Especificação dos limites dos indicadores: significa escolher critérios a serem medidos para que os impactos não comprometam a resiliência das trilhas e a qualidade da visita. Os prin- 
cipais critérios para a escolha dos limites dos indicadores foram a fragilidades dos ecossistemas, a presença de nascentes, o comprimento da trilha, a intensidade do impacto e a satisfação dos visitantes. Quanto mais frágil uma trilha, mais rígido será o limite do indicador. Os critérios citados para escolher o indicador foram baseados em observações de campo.

- $\quad$ Definição de freqüência do monitoramento: para definir a freqüência de monitoramento foi considerada a relevância do impacto. À proporção que o impacto é minimizado, a freqüência de monitoramento fica mais espaçada. Cabe ao órgão gestor fazer o monitoramento dos impactos das trilhas.

- $\quad$ Recomendações de ações de manejo: a ação de manejo é o que o órgão gestor deve fazer para reverter o impacto assim que o limite do indicador for ultrapassado.

- Grau de dificuldade das trilhas: apesar do grau de dificuldade das trilhas ser um componente subjetivo em função dos diversos fatores associados, tais como idade do visitante, condicionamento físico, dentre outros, neste trabalho foi utilizado escala de declividade proposta por Mitraud (2003), que determina: declividade $\leq 10 \%=$ sem dificuldade $; 10 \%<$ declividade $<20 \%=$ dificuldade mediana ; declividade $\geq 20 \%$ = grande dificuldade.

- $\quad$ Tempo aproximado do percurso: para o cálculo do tempo aproximado do percurso da trilha, percorreu-se toda a trilha em ritmo semelhante a um visitante jovem que percorre a trilha contemplando a paisagem. O tempo foi marcado em relógio com cronômetro.

\section{Resultados e discussão}

\section{Trilha do Poço das Moças}

A trilha do Poço das Moças tem ínicio a 5,7 quilômetros da sede do PARNASI. Seu comprimento total é de 151 metros, os quais os visitantes percorrem em aproximadamente 7 minutos. Esta trilha por não apresentar grau de dificuldade, é indicada para todas as idades, contudo não possibilita o trânsito de cadeiras de rodas devido à irregularidade do terreno e à falta de infra-estrutura adequada para portadores de deficiência. 
Essa trilha recebe impactos positivos significativos em decorrência da grande procura pelos visitantes para lazer, banho, relaxamento, contemplação, atividade física, pesquisa e misticismo. Segundo moradores da região, o lugar recebe este nome porque caçadores encontraram duas "moças encantadas" tomando banho lá e em seguida, sumiram sem deixar vestígios.

A trilha que leva ao Poço das Moças, apesar de apresentar baixa declividade - fator que pode evitar a maximização dos impactos negativos apresenta percursos com larguras excessivas, que variam de 1, 70 a 3 metros. Lechner (2006) sugere largura entre $0,60 \mathrm{~m}$ e $0,95 \mathrm{~m}$ para as trilhas utilizadas apenas por pedestres. O indicador largura da trilha é um dos mais úteis para se avaliar a deterioração da mesma (Barros, 2003), além de ser fácil e barato de ser monitorado. Por ele percebe-se que a trilha do Poço das Moças é a mais freqüentada e aparentemente a mais degradada do parque.

Os impactos negativos mais evidentes encontrados nessa trilha foram: clareiras, alargamento da trilha, trilhas secundárias, árvores danificadas, excesso de visitantes, barulho, odor desagradável, e lixo. Santos (2006), ao estudar a tipificação do lixo do PARNASI, constatou que o Poço das Moças estava recebendo a maior quantidade de lixo do parque, com $85 \%$ do total de lixo recolhido entre os meses de Maio e Agosto de 2006. As lixeiras utilizadas no parque não possuem tampas e podem ser facilmente escaladas por marsupiais como os gambás e as cuícas, que depois não conseguem sair. Estes animais podem morrer afogados se houver chuvas fortes (Pontes, 2006). As lixeiras usadas em trilhas e em outros locais nas unidades de conservação devem ser projetadas para impedir o acesso de animais silvestres ao seu interior.

Todos os impactos encontrados no Poço das Moças são decorrentes do uso público desordenado falta de gestão, de programas visando a sensibilização dos freqüentadores, de fiscalização e ausência de guias locais. A implementação de tais ações são sugeridas como formas de manejar e minimizar os impactos negativos (Quadro 1).

Quadro 1- Matriz para o Planejamento da "Trilha do Poço das Moças"

\begin{tabular}{|c|c|c|c|c|c|}
\hline \multicolumn{2}{|c|}{ Indicadores de impacto } & $\begin{array}{c}\text { Limite } \\
\text { aceitável }\end{array}$ & $\begin{array}{c}\text { Forma de } \\
\text { coleta }\end{array}$ & $\begin{array}{c}\text { Freqüência de } \\
\text { monitoramento }\end{array}$ & $\begin{array}{c}\text { Ações de } \\
\text { manejo }\end{array}$ \\
\hline \multirow{2}{*}{$\begin{array}{c}\text { Indicadores } \\
\text { recreativos }\end{array}$} & $\begin{array}{c}\text { 1-visitantes } \\
\text { (n⿳⺈冂䒑s) }\end{array}$ & $\begin{array}{c}25 \text { pessoas } \\
\text { por vez }\end{array}$ & $\begin{array}{c}\text { Contagem } \\
\text { direta }\end{array}$ & $\begin{array}{c}\text { Finais de semana e e } \\
\text { feriados }\end{array}$ & $\begin{array}{c}\text { Guias locais; } \\
\text { fiscalização; }\end{array}$ \\
\cline { 2 - 6 } & (litros/ semana) chão & $\begin{array}{c}3 \text { litros por } \\
\text { semana }\end{array}$ & Coleta manual & Semanal & $\begin{array}{c}\text { Educação e } \\
\text { Interpretação } \\
\text { Ambiental; }\end{array}$ \\
\hline
\end{tabular}




\begin{tabular}{|c|c|c|c|c|c|}
\hline \multirow{2}{*}{$\begin{array}{l}\text { Indicadores } \\
\text { físicos }\end{array}$} & $\left|\begin{array}{c}\text { 3- trilhas } \\
\text { secundárias (nْ } \\
\text { semestre) }\end{array}\right|$ & nenhuma & $\begin{array}{l}\text { Contagem } \\
\text { direta }\end{array}$ & Mensal & $\begin{array}{l}\text { Fechamento das } \\
\text { trilhas secundárias; } \\
\text { Recuperação da } \\
\text { vegetação }\end{array}$ \\
\hline & $\begin{array}{l}\text { 4- largura da } \\
\text { trilha (m) }\end{array}$ & $\begin{array}{l}\text { Até } 0,95 \\
\text { metros }\end{array}$ & Medição direta & Semestral & $\begin{array}{l}\text { Fazer com que os } \\
\text { visitantes andem } \\
\text { em fila indiana }\end{array}$ \\
\hline $\begin{array}{c}\text { Indicadores } \\
\text { ambientais }\end{array}$ & $\begin{array}{c}\text { 5- árvores } \\
\text { danificadas } \\
\text { (n\%semestre) }\end{array}$ & $\begin{array}{c}2 \text { por } \\
\text { semestre }\end{array}$ & $\begin{array}{l}\text { Contagem } \\
\text { direta }\end{array}$ & Semestral & $\begin{array}{l}\text { Fiscalização; } \\
\text { Educação e } \\
\text { Interpretação } \\
\text { Ambiental }\end{array}$ \\
\hline
\end{tabular}

Fonte: Pesquisa adaptada de Takahashi; Cegana (2006)

\section{Trilha da Gruta da Serra}

A trilha da Gruta da Serra inicia-se a aproximadamente 32 metros da entrada da trilha do Poço das Moças. Seu comprimento total é de 222 metros, os quais os visitantes percorrem em aproximadamente 16 minutos. Classifica-se o grau de dificuldade desta trilha como inexistente em quase toda sua extensão e de grande dificuldade nos 45 metros finais da trilha, na descida em direção ao banho na "Gruta da Serra". Dessa maneira, os 177 metros iniciais são indicados para pessoas de todas as idades; já no trecho final, recomenda-se que crianças só tenham acesso acompanhadas de pessoas adultas, devido ao risco de acidente.

Na trilha da Gruta da Serra, os impactos negativos mais evidenciados foram: árvores danificadas por visitantes, trilhas secundárias, raízes expostas e alargamento da trilha. A largura da trilha varia de 2,60 a 3 metros.

Nos 45 metros finais da trilha encontraram-se muitas raízes expostas e uma descida muito íngreme que pode provocar acidentes graves. No final da trilha encontra-se uma nascente, cujo paredão encontra-se riscado pela ação de vândalos.

Foi constatado, através das entrevistas com os visitantes que a Gruta da Serra é um dos locais preferidos por eles devido a sua beleza cênica e ao banho na nascente. Os impactos positivos mais evidentes dessa trilha é a contemplação, a atividade física, o banho e o relaxamento.

Os impactos negativos mais evidentes na trilha da Gruta da Serra foram: número de visitantes, lixo, clareiras, alargamento das trilhas e árvores riscadas. Estes impactos são decorrentes, principalmente, da ausência de ferramentas de planejamento e gestão. Para minimizar os impactos negativos 
desta trilha, recomenda-se a implementação de ações de manejo contidas na matriz de monitoramento desta trilha, tais como guias locais, fiscalização, educação e interpretação ambiental, isolamento da área desmatada para a recuperação da vegetação, orientação aos visitantes para que andem em fila indiana e implementação de placas de conteúdo educativo (Quadro 2).

Quadro 2 - Matriz para o Planejamento da "trilha da Gruta da Serra"

\begin{tabular}{|c|c|c|c|c|c|}
\hline \multicolumn{2}{|c|}{ Indicadores de impacto } & Limite & Forma de & Freqüência de & Ações de manejo \\
\hline \multirow{2}{*}{$\begin{array}{l}\text { Indicadores } \\
\text { recreativos }\end{array}$} & $\begin{array}{l}\text { 1- visitantes } \\
\text { (n\%/semana) }\end{array}$ & $\begin{array}{l}8 \text { pessoas } \\
\text { por vez }\end{array}$ & $\begin{array}{c}\text { Contagem } \\
\text { direta }\end{array}$ & $\begin{array}{c}\text { Finais de semana e } \\
\text { feriados }\end{array}$ & $\begin{array}{l}\text { Guias locais; } \\
\text { fiscalização }\end{array}$ \\
\hline & $\begin{array}{l}\text { 2- lixo no chão } \\
\text { (unidade/ } \\
\text { semana) }\end{array}$ & $\begin{array}{ll}5 & \text { unidades } \\
\text { por semana }\end{array}$ & $\begin{array}{l}\text { Coleta } \\
\text { manual }\end{array}$ & Semanal & $\begin{array}{c}\text { Educação e } \\
\text { Interpretação } \\
\text { Ambiental; }\end{array}$ \\
\hline \multirow{2}{*}{$\begin{array}{l}\text { Indicadores } \\
\text { físicos }\end{array}$} & $\begin{array}{l}\text { 3- clareira ( } \mathrm{n}^{\circ} / \\
\text { semestre) }\end{array}$ & nenhuma & $\begin{array}{c}\text { Contagem } \\
\text { direta }\end{array}$ & semestral & $\begin{array}{l}\text { Isolamento da área } \\
\text { desmatada para } \\
\text { a recuperação da } \\
\text { vegetação }\end{array}$ \\
\hline & $\begin{array}{l}\text { 4- largura } \\
\text { da trilha (m/ } \\
\text { semestre) }\end{array}$ & Até $0,95 \mathrm{~m}$ & $\begin{array}{c}\text { Medição } \\
\text { direta }\end{array}$ & Semestral & $\begin{array}{l}\text { Orientar os visitantes } \\
\text { para que andem em } \\
\text { fila indiana }\end{array}$ \\
\hline $\begin{array}{c}\text { Indicadores } \\
\text { ambientais }\end{array}$ & $\begin{array}{c}\text { árvores riscadas } \\
\quad(\mathrm{n} \% \mathrm{ano})\end{array}$ & $\begin{array}{c}1 \text { por } \\
\text { semestre }\end{array}$ & $\begin{array}{l}\text { Contagem } \\
\text { direta }\end{array}$ & Anual & $\begin{array}{c}\text { Placas de conteúdo } \\
\text { educativo }\end{array}$ \\
\hline
\end{tabular}

Fonte: Pesquisa adaptada de Takahashi; Cegana (2006)

Convém ressaltar que as trilhas estudadas não estão de acordo com os parâmetros de largura sugeridos por Lenchner (2006) - 0,60m à 0,95m.

\section{Considerações finais}

A metodologia LAC - Limite Aceitável de Câmbio foi eficiente para selecionar os principais indicadores de impacto, escolher os limites dos indicadores e identificar as ações de manejo fundamentais para minimizar e reverter os impactos em cada trilha estudada.

Os danos atribuídos ao uso público devem-se principalmente a uma ineficiente gestão dos recursos naturais e humanos. Para que a gestão do 
parque possa ser bem sucedida é necessário que seus gestores apliquem no cotidiano o planejamento e monitoramento dos impactos aqui expostos. As matrizes de monitoramento das trilhas propostas neste estudo são ferramentas importantes para a proteção dos recursos naturais, uma vez que pode auxiliar aos administradores do parque na seleção de estratégias de manejo que garantam a sustentabilidade dos ecossistemas. Para sua aplicação são necessários apenas uma gestão eficiente e recursos humanos. Os recursos humanos podem ser provenientes da Brigada do Parque, no período de contratação, de Programas de Voluntariado e de parcerias com condutores locais e universidades.

O PARNASI não tem aplicado instrumentos legais para compatibilizar os interesses de conservação e de uso público, tais como desapropriações e compensações ambientais. A falta de recursos financeiros, de uma gestão eficiente e de vontade política vem acarretando na degradação dos recursos do parque.

Uma vez que já está ocorrendo uso público na ausência do Plano de Manejo, é urgente o estudo que relacione a ocorrência das espécies de fauna e flora estudadas com as áreas de visitação, porque caso as trilhas estejam causando danos à fauna e à flora, principalmente às espécies endêmicas e ameaçadas de extinção, elas devem ser fechadas até a mitigação do problema.

\section{Referências}

AMÂNCIO, E; RAMOS, L. Diversidade de artrópodos de solo em três áreas da Serra de Itabaiana, Sergipe. Publicações Avulsas do Centro Acadêmico Livre de Biologia, Universidade Federal de Sergipe, São Cristóvão, n.1, p. 41-46, 1997.

BARROS, M.I.A. Caracterização da Visitação, dos Visitantes e Avaliação dos Impactos ecológicos e Recreativos do Planalto do Parque Nacional do Itatiaia. Piracicaba, Universidade de São Paulo, 2003. 121p. (Dissertação - Mestrado em Ciências Florestais).

CARVALHO, C. M.;VILAR, J. C. Levantamento da Biota do Parque Nacional Serra de Itabaiana. Biologia Geral e Experimental, São Cristóvão, 2005.

DIAS, S.C.; BRESCOVIT, A.D. Microhabitat selection and co-occurrence of Pachistopelma rufonigrum Pocock (Araneae, Theraphosidae) and Nothroctenus fuxico sp. nov. (Araneae, Ctenidae) in tank bromeliads from Serra de Itabaiana, Sergipe, Brazil. Revista Brasileira de Zoologia, n.21. p.789-796, 2004.

FERNANDES, A.C.M; OLIVEIRA, E.F. Diversidade na dieta e aspectos reprodutivos de duas espécies simpátricas e sintópicas de Tropidurus da Serra de Itabaiana, Sergipe (Sauria: ropiduridae). Publicações Avulsas do Centro Acadêmico Livre de Biologia, Universidade Federal de Sergipe, São Cristóvão, n.1, p.35-40, 1997. 
LECHNER, L. Planejamento, Implantação e Manejo de Trilhas em Unidades de Conservação. Cadernos de Conservação. Paraná: Fundação $\mathbf{O}$ Boticário de Proteção à Natureza, n.3. jun. 2006.

MITRAUD, S. Monitoramento e controle de impactos de visitação. In: Manual de Ecoturismo de Base Comunitária: ferramentas para um planejamento responsável. Brasília: WWF Brasil, 2003.

PONTES, J A. L. Planejamento, manejo de trilhas e impactos na fauna. In: I Congresso Nacional de Planejamento e Manejo de Trilhas, 2006, Rio de Janeiro. Anais... Rio de Janeiro, 2006. CDROM.

RAMOS, L.; DENISSON, S. Notas sobre os hábitats e microhábitats de duas espécies simpátricas de lagartos do gênero Tropidurus da Serra de Itabaiana, Sergipe (Sauria: Tropiduridae). Publicações Avulsas do Centro Acadêmico Livre de Biologia, Universidade Federal de Sergipe, São Cristóvão, n.1, 29-34, 1997.

SANTOS, C. Tipificação do lixo no Parque Nacional Serra de Itabaiana. São Cristóvão: Universidade Federal de Sergipe, 2006. (Monografia - Engenharia Agronômica).

SOBRAL, I.S; GOMES, L. J.; HOLANDA, F. S. Indicadores para o planejamento de uso sustentável do Parque Nacional Serra de Itabaiana no Estado de Sergipe . Revista Eisforia. Florianópolis, n. 1, v. 5:18-33, 2007.

STANKEY, G.H.; COLE, D.N.; LUCAS, R.C; PETERSEN, M. E;. FRISSELI, S.S. The Limits of Acceptable Change (LAC) system for wilderness planning. General Technical Report INT. USDA.Forest Service, Ogden, n. 176, p.1-37, 1985.

TAKAHASHI, L. Y.; CEGANA, C. Curso Uso público em Unidades de Conservação. Paraná: Fundação O Boticário de Proteção à Natureza, 2006.

TAKAHASHI, L. Y. Monitoramento de indicadores de impactos nas trilhas e percepção dos visitantes em Unidades de Conservação. In: I Congresso Nacional de Planejamento e Manejo de Trilhas, 2006, Rio de Janeiro. Anais... Rio de Janeiro, 2006. CD-ROM.

VICENTE, A.; ARAÚJO, G.M.M.; LÍRIO JR, G.P; SANTOS, S.C. Descrição parcial e preliminar dos hábitats da Serra de Itabaiana, Sergipe. Publicações Avulsas do Centro Acadêmico Livre de Biologia. São Cristóvão, 1997.

Ivana Silva Sobral Oliveira - Bióloga pela Universidade Federal de Sergipe (2005); Msc. em Agroecossistemas/ UFS (2008), Professora substituta do Departamento de Biologia da UFS (2008) 